\title{
Cana-de-açúcar: Avaliação da taxa de aplicação e deposição do herbicida glifosato
}

\author{
Euripedes B. Rodrigues ${ }^{1}, 0$ tavio J. G . Abi Saab ${ }^{2} \&$ Marco A. G andolfo ${ }^{1}$
}

\begin{abstract}
RESUMO
No Brasil, o uso de agrotóxicos consumirá, anualmente, mais de seis milhões de $\mathrm{m}^{3}$ de água como veículo, na cultura da cana-de-açúcar. 0 menor volume de calda aumenta a autonomia e a capacidade operacional dos pulverizadores, diminuindo o risco de perdas por escorrimento. Este trabalho teve como objetivo comparar diferentes taxas de aplicação do glifosato quanto à eficiência no controle e à deposição da calda em plantas daninhas na operaçã̃o de "repasse" ou "catação". Foram executados oito tratamentos com quatro repetições distribuídos em blocos ao acaso. As taxas de aplicação avaliadas foram: $8,8,73,96,7,190,260,380$ e $467 \mathrm{~L} \mathrm{ha}^{-1}$, aplicadas com equipamentos costal de acionamento manual, costal pressurizado e micronizador rotativo tipo CDA. Realizou-se a eficiência no controle das plantas daninhas considerando-se o efeito das aplicações em cada um dos tratamentos. A avaliação qualitativa, comparando-se os depósitos obtidos em cada um dos tratamentos, foi feita pela pulverização sobre as plantas daninhas de uma solução de água e cloreto de sódio com os mesmos equipamentos e nas mesmas condições. $0 \mathrm{~s}$ resultados indicam a possibilidade de utilização de menores volumes de aplicação sem prejuízo da qualidade.
\end{abstract}

Palavras-chave: tecnologia de aplicação, agrotóxicos, herbicidas, Saccharum spp

\section{Sugarcane: Evaluation of application rates and deposition of the glyphosate herbicide}

\begin{abstract}
The growing use of pesticides in agriculture will consume more than six million cubic meters of water annually in Brazil, on sugarcane crop alone. The minor volumes of water can give an increase in autonomy and capacity of sprayer, and reduces the chance of loss by runoff. This work has the purpose to compare different rates of the glyphosate herbicide application, concerning efficiency of control and volume deposition on weeds, at operations of "repass" on sugarcane crop. Eight treatments with four replications were studied in randomized blocks. Application rates evaluated were: 8.8, 73, 96.7, 190, 260, 380 and $467 \mathrm{~L} \mathrm{ha}^{-1}$, using a pressurized knapsack sprayer and another with hand operation and a rotative micronizer type CDA. Efficiency on weed control was evaluated considering obtained application effects on each treatment. Q ualitative evaluation, comparing obtained deposition on each treatment, was done spraying on weeds with a solution of water plus sodium chloride, using the same equipament and conditions. The results showed the possibility to use lower flow rate of application without problems over the quality.
\end{abstract}

Key words: application technology, pesticides, spraying, Saccharum spp 


\section{INTRODUÇÃO}

A cultura da cana-de-açúcar tem expressiva participação na economia, não só pela produção de açúcar e de álcool combustível, como também pelo fornecimento de matéria-prima para a indústria química, subprodutos utilizados na alimentação animal, na produção de fertilizantes, tal como na grande capacidade instalada de geração de energia elétrica.

A quase totalidade dos agrotóxicos aplicados na agricultura utiliza como veículo a água, com ou sem o auxílio de aditivos. Gandolfo et al. (2008) avaliaram que até o ano de 2017 somente a cultura de cana-de-açúcar, permanecendo a evolução prevista, consumirá anualmente em aplicação de agrotóxicos de modo convencional no Brasil, a cifra de seis milhões de $\mathrm{m}^{3}$ de água.

As plantas daninhas são um dos principais componentes que interferem negativamente no desenvolvimento e na produtividade da cultura da cana-de-açúcar, Kuva et al. (2003). As reduções de produtividade podem variar desde 20 a $86 \%$ (Kuva et al., 2000).

Uma das operações comuns no controle de plantas daninhas em cana-de-açúcar é a de "catação" ou "repasse", que consiste no uso de herbicidas aplicados após o controle químico efetuado em área total, através de máquina costal manual.

Esta operação objetiva a limpeza de estradas rurais, carreadores, bordas dos talhões e entre linhas da cultura, ganhando maior importância com a perspectiva de adoção da colheita mecanizada, facilitando o deslocamento das máquinas e a limpeza do material colhido.

Para o controle do problema fitossanitário as gotas produzidas devem ter boa uniformidade de diâmetro, minimizando a percentagem de gotas menores que $1001 / 4 \mathrm{~m}$, e que estão mais sujeitas à deriva, ou aquelas excessivamente grandes que, após o impacto na superfície tratada ricocheteiam e se fragmentam em gotas menores ou escorrem para o solo, devido ao uso de volume excessivo de calda. (Cunha et al., 2003).

O espectro de gotas de pontas de pulverização hidráulicas de jato plano (standard e antideriva) e de jato cônico vazio, em diferentes pressões de pulverização, foi medido por meio de um analisador a laser de gotas em tempo real. Os resultados permitiram concluir que: o espectro de gotas foi influenciado pela vazão nominal das pontas e pela pressão de pulverização; o potencial de deriva das pontas foi alto; o uso de pontas de pulverização antideriva aumentou o diâmetro das gotas, auxiliando na redução da deriva nas pulverizações e a avaliação do espectro de gotas, empregando-se a técnica da difração do raio laser, mostrou-se rápida e precisa, conforme Cunha et al. (2007).

É um aspecto a ser considerado, pois as gotas menores estão sujeitas a um potencial de deriva alto, como afirmam Cunha et al. (2005) que para avaliar a deposição e a deriva de calda fungicida em feijoeiro, testaram pontas de pulverização (jato plano standard e jato cônico vazio) com dois volumes de aplicação, analisaram a distribuição de um traçador nas posições superior e inferior da planta pela técnica da espectrofotometria, enquanto a deriva foi avaliada através de alvos artificiais, posicionados fora da área alvo.
A utilização de substância por definição considerada tóxica, em doses muito menores que a utilizada visa, por sua vez, estimular o desenvolvimento vegetal e é conhecida como "efeito hormético", segundo Calabrese \& Baldwin (2002). O efeito hormético é observado em todos os grupos de organismos como bactérias e fungos, plantas superiores e animais. (Calabrese, 2005).

Os estímulos são verificados em características de crescimento como ganho de peso, altura, comprimento e área foliar e/ou características internas como teor protéico e níveis de açúcares, em culturas de cana de açúcar, soja, milho, cevada, centeio, eucalipto e pinheiro. Em geral, os herbicidas empregados nos testes foram: MSMA, oxifluorfen, terbacil, simazine e glifosato.

Tendo em vista essas características, torna-se clara a necessidade de desenvolver estratégias diferenciadas para cada tipo de aplicação, havendo ainda muito a se pesquisar e utilizar a respeito da formação, transporte e deposição das gotas, a fim de conseguir a colocação correta do produto no alvo.

O uso de menor volume de calda aumenta a autonomia e a capacidade operacional dos pulverizadores e diminui o risco de perdas por escorrimento. A busca por técnicas de redução de volume de água deverá ser incrementada e nas regiões de grande potencial agrícola, com distribuição irregular de água, as técnicas de baixo volume deverão ser priorizadas para que não se ampliem a falta deste recurso.

Com o objetivo de avaliar a redução do volume de calda aplicado, este trabalho comparou taxas de aplicação do herbicida glifosato, quanto à eficiência no controle e a deposição da calda em plantas daninhas na operação de repasse em cana-de-açúcar.

\section{Material e MÉTODOS}

As determinações de campo foram realizadas durante o período compreendido entre dezembro de 2008 e março de 2009, em área da Universidade Estadual do Norte do Paraná (UENP), Campus Luiz Meneghel, localizada no município de Bandeirantes, Estado do Paraná, cujo centróide está a $50^{\circ} 21^{\prime} 23^{\prime}$ 'W de longitude e $23^{\circ} 06^{\prime} 30^{\prime \prime} \mathrm{S}$ de latitude, altitude aproximada de $400 \mathrm{~m}$.

O clima, pela classificação de Köeppen, é Cfa, ou seja, subtropical úmido, mesotérmico com verão quente, estiagem no inverno, média de $30 \mathrm{~mm}$ no mês mais seco e geadas pouco frequentes. A precipitação média anual é de $1.300 \mathrm{~mm}$.

Os pulverizadores costais utilizados foram: acionamento manual (Am), com capacidade para $20 \mathrm{~L}$; pressurizado $(\mathrm{P})$ com tanque de aço inoxidável de $18 \mathrm{~L}$, sendo que em ambos a pressão de operação foi de $200 \mathrm{kPa}$, e um pulverizador munido de micronizador rotativo (R), tipo CDA (Controlled Droplets Application), depósito em polietileno de alta densidade de 12 $\mathrm{L}$, equipado com chapéu protetor e três tipos de pontas que produzem, segundo o fabricante, gotas finas (R5), gotas médias (R6) e gotas grossas (R7).

Oito tratamentos com quatro repetições distribuídos em blocos ao acaso foram realizados em área de Nitossolo. Os tratamentos se constituíram de pulverizações com herbicida 
Glifosato, na dose equivalente a $2 \mathrm{~L} \mathrm{ha}^{-1}$ de produto comercial, com $48 \%$ de ingrediente ativo por litro segundo Amarante Júnior $\&$ Santos (2002).

Os tratamentos estão apresentados na Tabela 1.

Tabela 1. Tratamentos, equipamentos, taxas de aplicação e pontas utilizadas

\begin{tabular}{cccc}
\hline Tratamento & Equipamento & $\begin{array}{c}\text { Taxa de } \\
\text { Aplicação } \\
\left(\mathbf{L ~ h a}^{-1} \mathbf{)}\right.\end{array}$ & Ponta \\
Am1 & Acionamento manual & 260 & AXI 110015 \\
Am2 & Acionamento manual & 467 & AXI 11003 \\
P3 & Pressurizado & 190 & AXI 110015 \\
P4 & Pressurizado & 380 & AXI 11003 \\
R5 & CDA gotas finas & 8,8 & CDA \\
R6 & CDA gotas medias & 73 & CDA \\
R7 & CDA gotas grossas & 96,7 & CDA \\
T8 & Testemunha & Testemunha & Testemunha \\
\hline
\end{tabular}

* Categorias de tamanho das gotas segundo norma ASAE S572 (ASAE, 2000)

A área útil das parcelas para medir a eficiência de controle e para análise dos depósitos, foi de $18 \mathrm{~m}^{2}$, correspondendo a $6 \mathrm{~m}$ de comprimento por $3 \mathrm{~m}$ de largura mais $1,5 \mathrm{~m}$ de bordadura; portanto, uma área total do experimento de $864 \mathrm{~m}^{2}$.

No inicio da aplicação foram anotados, em cada tratamento, o horário, a temperatura e a umidade relativa, com a finalidade de subsidiar a análise com um relógio termoigrômetro da marca minipa, modelo MT- 241 e se pode observar que todas as aplicações foram feitas em condições adversas, conforme apresentado na Tabela 2 .

Tabela 2. Taxas de aplicação, horário, temperaturas e umidade relativa, anotados na execução dos tratamentos

\begin{tabular}{ccccc}
\hline Tratamento & $\begin{array}{c}\text { Taxas de } \\
\text { Aplicação } \\
\text { (L ha-1) }\end{array}$ & Horário & $\begin{array}{c}\text { Temperatura } \\
\left.\text { ( }{ }^{\circ} \mathbf{C}\right)\end{array}$ & $\begin{array}{c}\text { Umidade } \\
\text { relativa } \\
\text { (\%) }\end{array}$ \\
Am1 & 260 & $11 \mathrm{~h} ; 07 \mathrm{~min}$ & 31,9 & 58 \\
Am2 & 467 & $11 \mathrm{~h} ; 15 \mathrm{~min}$ & 32,5 & 60 \\
P3 & 190 & $10 \mathrm{~h} ; 40 \mathrm{~min}$ & 31,9 & 62 \\
P4 & 380 & $10 \mathrm{~h} ; 25 \mathrm{~min}$ & 34,9 & 52 \\
R5 & 8,8 & $12 \mathrm{~h} ; 05 \mathrm{~min}$ & 35,6 & 46 \\
R6 & 73 & $11 \mathrm{~h} ; 55 \mathrm{~min}$ & 34,3 & 49 \\
R7 & 96,7 & $11 \mathrm{~h} ; 35 \mathrm{~min}$ & 34,5 & 48 \\
\hline
\end{tabular}

Realizou-se a eficiência no controle das plantas daninhas considerando-se o efeito das aplicações de cada um dos tratamentos, sobre a espécie capim amargoso (Digitaria insularis) de controle mais difícil que as plantas daninhas predominantes na área; capim argentino (Sorghum halepense), capim branco (Chloris polydactyla) e capim colonião (Panicum maximum), utilizando-se a escala de eficiência proposta pela SBCPD (2000). As avaliações foram efetuadas em três épocas distintas após a aplicação do herbicida, a saber: 07, 15 e aos 30 dias após aplicação.

As plantas daninhas avaliadas se encontravam em pleno desenvolvimento e em fase de preflorescimento e as avaliações, segundo a proposta da SBCPD (2000), foram feitas de forma visual e com três avaliadores.

No período citado avaliou-se também a possibilidade de ocorrência de fitotoxicidade do produto glifosato na cana-de- açúcar, nas condições de aplicação. O produto foi aplicado ao acaso em jato dirigido nas entrelinhas, também em oito tratamentos e com quatro repetições e a avaliação foi feita utilizando-se a mesma metodologia.

A cana-de-açúcar estava com quatro meses de rebrota após a colheita manual.

Os conceitos aplicados às avaliações de controle, segundo a escala de eficiência proposta pela Sociedade Brasileira da Ciência das Plantas Daninhas, SBCPD (2000), estão descritos na Tabela 3 .

\begin{tabular}{|c|c|}
\hline Conceito & Descrição \\
\hline A & Controle excelente ou total da espécie em estudo \\
\hline B & Controle bom, aceitável para infestação da área \\
\hline $\mathrm{C}$ & Controle moderado, insuficiente para a infestação da área \\
\hline D & Controle deficiente ou inexpressivo \\
\hline E & Ausência de controle \\
\hline
\end{tabular}

Além das avaliações sobre a eficiência no controle das plantas daninhas, já mencionadas, também se realizou uma avaliação qualitativa comparando-se os depósitos obtidos em cada um dos tratamentos.

Esta comparação se realizou pela pulverização de uma solução composta por água e $2 \%$ de cloreto de sódio, nas mesmas condições de taxa de aplicação que os tratamentos descritos. Após a aplicação da solução de água e cloreto de sódio, coletaram-se 10 folhas da planta daninha considerada nas avaliações de eficiência.

As folhas foram colocadas em sacos plásticos identificados e em cada um se colocou um volume de $100 \mathrm{~mL}$ de água deionizada; após a colocação da água, esses sacos foram agitados 30 segundos, para lavagem completa das folhas pela água; enfim, mediu-se a condutividade elétrica da água de lavagem pela imersão de um condutivímetro com escala de medição de 0 a 1999 mS.

Foram coletadas, também, 10 folhas da espécie da planta daninha considerada em área sem aplicação, para a lavagem, com o mesmo volume de água deionizada e determinação de sua condutividade elétrica inicial. Esses valores foram subtraídos dos valores de condutividade elétrica obtidos com os tratamentos, para que o valor resultante corresponda somente às diferenças entre os tratamentos.

As folhas tiveram suas áreas medidas com os respectivos valores de condutividade elétrica, divididos pelas áreas das folhas correspondentes aos tratamentos, a fim de se obter a condutividade elétrica proporcional à área foliar coletada, conforme proposto por Abi Saab (2000).

Para avaliar o processo de pulverização, os fatores mãode-obra, máquina, material, meio e método, foram submetidos ao "check list", ferramenta de qualidade proposta por Santos \& Maciel (2006), no Núcleo de Investigação em Tecnologia de Aplicação de Agrotóxicos e Máquinas Agrícolas da UENP Campus Luiz Meneghel. Os equipamentos foram operados sempre pelo mesmo operador com o qual foram calibrados.

Constatou-se ausência de manômetro no equipamento Pressurizado $(\mathrm{P})$, sendo que o mesmo foi equipado com um 
manômetro analógico com escala de $1365 \mathrm{kPa}$ e as pontas de pulverização, substituídas por novas, em que as pontas do pulverizador de acionamento manual (Am), também foram substituídas.

Os resultados da eficiência no controle das plantas daninhas e os valores de condutividade elétrica obtidos em cada um dos tratamentos, foram submetidos à análise de variância e suas médias comparadas pelo teste de Tukey a $5 \%$ de probabilidade.

\section{Resultados E Discuss Ão}

Submetendo-se a eficiência no controle das plantas daninhas à análise estatística, Tabela 4 , foram encontrados os resultados seguintes:

Tabela 4. M édia das porcentagens de eficiência e conceitos de controle do capim amargoso (D igitaria insularis), aos 7, 15 e 30 d.a.a. (dias após aplicação)

\begin{tabular}{|c|c|c|c|c|c|c|}
\hline \multirow[b]{2}{*}{ Trat. } & \multicolumn{2}{|c|}{07 d.a.a. } & \multicolumn{2}{|c|}{15 d.a.a. } & \multicolumn{2}{|c|}{30 d.a.a. } \\
\hline & $\begin{array}{l}\text { Cont. } \\
(\%)\end{array}$ & Conc. & $\begin{array}{l}\text { Cont. } \\
(\%)\end{array}$ & Conc. & $\begin{array}{l}\text { Cont. } \\
(\%)\end{array}$ & Conc. \\
\hline *Aml & $57,5 \mathrm{a}$ & C & $92,5 a$ & B & $92,5 \mathrm{a}$ & B \\
\hline *Am2 & $55,0 \mathrm{a}$ & C & $85,0 \mathrm{bc}$ & B & $87,5 \mathrm{ab}$ & B \\
\hline *P3 & $55,0 \mathrm{a}$ & C & $87,5 \mathrm{ab}$ & B & $90,0 \mathrm{ab}$ & B \\
\hline *P4 & $52,5 \mathrm{a}$ & C & $80,0 \mathrm{C}$ & B & $85,0 \mathrm{~b}$ & B \\
\hline *R5 & $60,0 \mathrm{a}$ & C & $92,5 \mathrm{a}$ & B & $92,5 \mathrm{a}$ & B \\
\hline *R6 & $60,0 \mathrm{a}$ & C & $87,5 a b$ & B & 92,5 a & B \\
\hline *R7 & $60,0 \mathrm{a}$ & C & 85,0 bc & B & $90,0 a b$ & B \\
\hline *T8 & $0,00 \mathrm{~b}$ & E & $0,00 \mathrm{~d}$ & E & $0,00 \mathrm{c}$ & $E$ \\
\hline C.V. & $8,73 \%$ & & $3,85 \%$ & & $3,02 \%$ & \\
\hline
\end{tabular}

As médias seguidas da mesma letra não diferem entre si nas colunas (Tukey - $5 \%$ de probabilidade). Conceitos segundo proposta da SBCPD (2000)

* Am1- acionamento manual ponta 110015 e Am2 ponta 11003; P3-pressurizado ponta 110015 e P4 ponta 11003; R5 - Rotativo gotas finas, R6 - gotas medias e R7 - gotas grossas; T8 - Testemunha) Trat. - Tratamento; Cont. - Controle; Conc. - Conceito

Observou-se que, aos 7 dias após aplicação, todos os tratamentos diferiram da testemunha (8) e que não houve diferença significativa entre eles. $\mathrm{O}$ conceito $\mathrm{C}$, também obtido por todos os tratamentos, mostra que nesta fase o controle foi moderado e insuficiente para infestação da área, porém diferente da testemunha, que obteve conceito E, e/ou seja, ausência de controle, o que evidencia o início de resposta aos tratamentos.

A partir dos 15 dias após aplicação, começaram a aparecer diferenças entre os tratamentos e se fez necessário um estudo comparativo com os resultados obtidos no teste de condutividade elétrica, apresentados na Tabela 5.

Os resultados da condutividade elétrica demonstram diferença significativa entre o depósito sobre as plantas nas pulverizações feitas com maiores ou menores volumes, podendo-se deduzir que o fato das gotas menores, resultado das aplicações com as pontas de menor vazão (110 015) e a ponta rotativa de gotas de menor diâmetro (R5), produzirem uma cobertura foliar melhor, contrabalancem os menores volumes aplicados por elas.

Esta afirmação é reforçada quando se observa, no mesmo equipamento como no Pressurizado, que houve diferença estatística entre o P3 (110 015) e o P4 (110 03), este último dotado de pontas de maior vazão. $\mathrm{O}$ mesmo ocorreu quando
Tabela 5. Avaliação qualitativa dos valores de condutividade elétrica e eficiência de controle das plantas daninhas

\begin{tabular}{cccc}
\hline Tratamentos $^{*}$ & Condutividade & \multicolumn{2}{c}{ Controle } \\
\cline { 3 - 4 } & $\boldsymbol{\mu S}$ & $\mathbf{1 5}$ d.a.a. & $\mathbf{3 0}$ d.a.a. \\
Am1 & $2,36 \mathrm{ab}$ & $92,5 \mathrm{a}$ & $92,5 \mathrm{a}$ \\
Am2 & $2,17 \mathrm{ab}$ & $85,0 \mathrm{bc}$ & $87,5 \mathrm{ab}$ \\
P3 & $2,89 \mathrm{a}$ & $87,5 \mathrm{ab}$ & $90,0 \mathrm{ab}$ \\
P4 & $1,00 \mathrm{~b}$ & $80,0 \mathrm{c}$ & $85,0 \mathrm{~b}$ \\
R5 & $2,97 \mathrm{a}$ & $92,5 \mathrm{a}$ & $92,5 \mathrm{a}$ \\
R6 & $1,57 \mathrm{ab}$ & $87,5 \mathrm{ab}$ & $92,5 \mathrm{a}$ \\
R7 & $1,02 \mathrm{~b}$ & $85,0 \mathrm{bc}$ & $90,0 \mathrm{ab}$ \\
C.V. & $33,41 \%$ & $3,85 \%$ & $3,02 \%$ \\
\hline
\end{tabular}

As médias seguidas da mesma letra não diferem entre si nas colunas (Tukey - $5 \%$ de probabilidade), Conceitos segundo proposta da SBCPD (2000)

d.a.a. (dias após aplicação)

* Am1- acionamento manual ponta 110015 e Am2 ponta 11003; P3-pressurizado ponta 110015 e P4 ponta 11003; R5 - Rotativo gotas finas, R6 - gotas medias e R7 - gotas grossas

da utilização do micronizador rotativo quando equipado com ponta de maior vazão (R7) e gotas maiores.

Concorda-se com o relato de Gadanha Junior (2001), ao afirmar que a indústria de máquinas para aplicação de agrotóxicos tem buscado desenvolver equipamentos que apresentem exatidão na dose aplicada, diminuição das perdas por deriva e manutenção das condições seguras à operação e aos operadores.

Aos 15 dias após aplicação, a eficiência do controle foi menor nos pulverizadores que utilizaram as pontas de maior vazão Am2, P4 e R7, mantendo o observado nos depósitos analisados por condutividade elétrica, sendo que o tratamento P4 diferiu estatisticamente dos tratamentos Am1, P3, R5 e R6. A maior eficiência observada no uso das pontas de menor vazão se deve, provavelmente, à maior concentração do herbicida na calda.

Nas observações efetuadas aos 30 dias após aplicação, o tratamento $\mathrm{P} 4$ volta a se diferenciar, mantendo as diferenças ocorridas aos 30 dias porém cabe ressaltar que todos os tratamentos obtiveram o conceito B, controle bom, aceitável para infestação da área, conforme a escala de eficiência proposta da SBCPD (2000), descritos na Tabela 3.

A cultura da cana-de-açúcar não apresentou sintomas de fitotoxicidade nas avaliações feitas no mesmo período.

Ressalta-se que todas as aplicações foram feitas em condições de temperatura, horário e umidade relativa adversas, Tabela 3. A eficácia dos herbicidas é influenciada por fatores que afetam a absorção e a translocação desses compostos na planta. Com a diminuição da umidade relativa do ar e/ou com o aumento da temperatura, as gotas secam mais rapidamente e a absorção do produto diminui ou até mesmo cessa, afetando o desempenho biológico.

Com o objetivo de examinar a influência do orvalhoe do volume de calda de aplicaçãona eficiência de doses de glifosato para controle de Brachiara plantaginea, Roman et al. (2004) observaram interações significativas entre volume de calda, orvalho e dose de glifosato. $\mathrm{O}$ volume mais baixo $\left(100 \mathrm{~L} \mathrm{ha}^{-1}\right)$, resultou em melhor controle da espécie, principalmente quando foi usado na menor dose $\left(90 \mathrm{~g} \mathrm{ha}^{-1}\right)$. A presença de orvalho nas folhas causou reduções na atividade do produto, em especial quando aplicado na menor dose e combinado com maior volume de calda. 
Esses resultados repetem os encontrados neste trabalho em que a menor taxa de aplicação foi sempre mais eficiente no controle da Digitaria insularis; os tratamentos $\mathrm{Am}_{1,} \mathrm{P}_{3}$ e o $\mathrm{R}_{5}$ foram com taxas de aplicação de 260, 190, e 8,8 $\mathrm{L} \mathrm{ha}^{-1}$, respectivamente.

A diferença significativa entre os tratamentos e o tratamento P4 discorda da encontrada por Barcellos et al. (2005) que, em experimento realizado com a finalidade de estudar a eficiência de pontas de pulverização, testaram 5 pontas e 5 taxas de aplicação dos herbicidas acifluorfen e bentazon, aplicados em área total em taxas que variaram de 70 a $208 \mathrm{~L} \mathrm{ha}^{-1}$ e concluíram que a variação do tipo de ponta e taxas de aplicação não promoveu alterações significativas nos níveis de controle das plantas daninhas estudadas.

Nota-se que pelos herbicidas aqui utilizados, que trata-se de plantas daninhas de folhas largas o que, em geral, facilita a deposição de gotas sobre o alvo biológico, diferente do que normalmente ocorre nas gramíneas.

Costa et al. (2008) testando o efeito de pontas de pulverização na deposição e na dessecação de plantas de Brachiaria brizantha com glifosato, também avaliaram diferentes vazões e tamanho de gotas na deposição e afirmam que todas as pontas foram eficientes na dessecação das plantas, independentemente do volume utilizado (100 a $\left.200 \mathrm{~L} \mathrm{ha}^{-1}\right)$ e na dose de $1800 \mathrm{~g} \mathrm{ha}^{-1}$. Concluíram ainda que o resultado encontrado evidencia a possibilidade de redução do volume de aplicação e da dosagem do herbicida utilizado na dessecação de pastagens, com o que se concorda neste experimento.

Também Tomazela et al. (2006), avaliando a quantidade de calda de pulverização depositada nas folhas de Brachiaria plantaginea, em aplicações de pós-emergência precoce, em que se variou o volume de calda de pulverização, a densidade de plantas $\mathrm{m}^{-2}$ e o ângulo de posicionamento da ponta de pulverização na barra de aplicação, em três experimentos sendo que no primeiro os volumes utilizados foram de 1147,57; 860,68; 573,$78 ; 459,02 ; 344,27 ; 229,51 ; 114,75 ;$ e $57,37 \mathrm{~L} \mathrm{ha}^{-1}$ de calda de pulverização, com densidade de 600 plantas $\mathrm{m}^{-2}$.

As avaliações do depósito de calda de pulverização, na planta e no solo, foram feitas utilizando-se condutividade elétrica, encontrando-se que a porcentagem de depósito de calda de pulverização nas plantas de $B$. plantaginea, foi incrementada com a redução do volume de calda pulverizada por hectare, resultado compatível com o encontrado neste trabalho. O depósito de calda por planta foi maior nas densidades maiores de plantas.

Schcroder \& Loeck (2006) avaliaram a redução de volume de calda e dose do herbicida glifosate através do sistema de pulverização eletrostático aéreo. O sistema de pulverização eletrostático mostrou controle superior das plantas daninhas, com volume de calda de $10 \mathrm{~L} \mathrm{ha}^{-1}$ quando comparados com volumes de $30 \mathrm{~L} \mathrm{ha}^{-1}$ e dosagens de 930, 1178, 1426 e $1674 \mathrm{~g}$ de ingrediente ativo $\mathrm{ha}^{-1}$. As avaliações foram efetuadas 13 dias após o tratamento atribuindo notas percentuais, em que $100 \%$ correspondiam à morte de todas as plantas e zero, a plantas sem sintomas do herbicida resultado este semelhante ao encontrado neste trabalho.

O uso de menor volume de calda aumenta a autonomia e a capacidade operacional dos pulverizadores e diminui o risco de perdas por escorrimento. Somente na Usina de Açúcar e Álcool Bandeirantes S.A. (USIBAN), caso fosse adotada a redução de taxa de aplicação proposta dos atuais 450 para 8,8 $\mathrm{L} \mathrm{ha}^{-1}$, significaria $1,95 \%$ do volume aplicado atualmente.

Tal diminuição de perdas por escorrimento significaria, certamente, menor contaminação de águas superficiais.

A presença de moléculas de agrotóxicos em águas superficiais de três unidades paisagísticas (UP) com diferentes configurações de uso, numa microbacia hidrográfica de cabeceira em Agudo, RS, foi quantificada por Bortoluzzi et al. (2006), através de dois coletores semiautomáticos de água instalados no córrego de cada UP, onde se coletaram amostras por ocasião de chuvas, em três épocas da cultura do fumo: transplante, aterramento junto aos pés da cultura (planta com 6-10 folhas) e colheita.

Os autores concluíram que a qualidade das águas superficiais e as águas dos córregos margeadas por lavouras tendem a apresentar agrotóxicos e não se enquadram na classe I preconizada pelo CONAMA.

Grützmacher et al. (2008) monitoraram e avaliaram a presença de agrotóxicos na região sul do Estado do Rio Grande do Sul. Durante o cultivo do arroz irrigado foram coletadas, em cinco datas diferentes, três amostras de água do rio Piratini e quatro do canal São Gonçalo. Os autores encontraram resíduos de agrotóxicos nas águas dos locais estudados e concluíram que águas localizadas em pontos mais baixos apresentam maiores quantidades de resíduos.

Um modelo de retenção de herbicidas foi investigado por Pinho et al. (2006) em uma zona ripária; para isto, uma mistura de caulinita, atrazina e picloran em escoamento superficial simulado dentro de uma zona ripária estabelecida ao longo de plantações de pinheiros do nordeste do estado da Georgia, EUA. O modelo possibilitou estimar, com razoável precisão, a remoção de caulinita e atrazina da mistura em escoamento ao longo de zonas ripárias de $10 \mathrm{~m}$ de comprimento.

Os autores concluíram que a manutenção do horizonte 0 mostrou-se fundamental para remoção de contaminantes e que a concentração de caulinita foi a que mais decresceu enquanto a de picloran não foi significativamente reduzida.

Amarante Júnior \& Santos (2002) afirmam que, devido à rápida adsorção no solo, o glifosato não é facilmente lixiviado, sendo pouco provável a contaminação de águas subterrâneas e que, em raras ocasiões, o pesticida tem sido detectado em amostras de águas mas, em geral, isto ocorre em virtude da dificuldade de separação do composto e pelo fato de não ser considerado um contaminante aquático sério.

Apesar da menor intensidade do uso de agrotóxicos na cultura da cana-de-açúcar, comportamento semelhante, com relação ao menor índice de contaminação, é possível a drástica redução no uso da água como veículo proposta neste trabalho; além de diminuir o contato direto da água com o herbicida, provocará uma perda menor por escorrimento durante a aplicação.

É notória a necessidade urgente de maiores estudos de aplicação em área total e com os diversos produtos disponíveis para o controle de plantas invasoras na cana-de-açúcar e nas demais culturas. 
A natureza agradece pelo menor dano, já que ele é inevitável dentro do quadro atual de recursos tecnológicos e da necessidade de produção de alimentos e energia.

\section{CONCLUSÕES}

1. O método da condutividade elétrica mostrou resultados coerentes com os encontrados na avaliação de eficiência, no controle das plantas daninhas.

2. Mesmo aplicado em condições adversas de temperatura e umidade relativa o controle das plantas daninhas foi bom e aceitável em todos os tratamentos realizados.

3. A menor taxa de aplicação apresenta eficiência de controle igual à apresentada pela maior taxa de aplicação.

\section{Agradecimentos}

Os autores agradecem à UENP - Campus Luiz Meneghel, à UEL, à Fundação Araucária, à USIBAN e ao Dr. Robinson Osipe.

\section{LITERATURA CITADA}

Abi Saab, O. J. G. Avaliação de cobertura e depósitos de agrotóxicos em videiras com o uso de diferentes técnicas de aplicação e condições operacionais. Botucatu: UNESP, 2000. 84p. Tese Doutorado

Amarante Júnior, O. P.; Santos, T. C. R.; Glifosato: Propriedades, toxicidade, usos e legislação. Quimica Nova, v.25, n.4, p.589593, 2002.

ASAE - American Society of Agricultural Engineering. S572. Spray nozzle classification by droplet spectra. In: ASAE Standard, AUG99. St. Joseph: ASAE, 2000. p.389-91.

Barcellos, L. C.; Almeida, R. A.; Ferreira Leão, P. G.; Veloso Santos, V. R.; Czepak, C.; Fernandes, P. M. Desempenho do bico hidráulico boomjet 5880-3/4-2toc20 em aplicações de herbicida sobre urochloa decumbens (STAPF) R. Webster1. Pesquisa Agropecuária Tropical, v.35, n.3, p.199-205, 2005.

Bortoluzzi, E. C.; Rheinheimer, D. S.; Gonçalves, C. S.; Pellegrini, J. B. R.; Zanella, R.; Copetti, A. C. C. Contaminação de águas superficiais por agrotóxicos em unção do uso do solo numa microbacia hidrográfica de Agudo, RS. Revista Brasileira de Engenharia Agrícola e Ambiental, v.10, n.4, p.881-887, 2006.

Calabrese, E. J. Paradigm lost, paradigm found: The reemergence of hormesis as a fundamental dose response model in the toxicological sciences. Environmental Pollution, n. 138 p.378411, 2005.

Calabrese, E. J.; Baldwin, L. A. Applications of hormesis in toxicology, risk assessment and chemotherapeutics. Trends in Pharmacological Science, n.7, p.323-331, 2002.

Costa, N.V.; Rodrigues, A. C. P.; Martins, D.; Cardoso, L. A.;Silva, J. I. C. Efeito de pontas de pulverização na deposição e na dessecação em plantas de Brachiaria brizantha. Planta Daninha, v.26, n.4, p.923-933. 2008.

Cunha, J. P. A. R.; Teixeira, M. M.; Coury, J. R.; Ferreira, L. R. Avaliação de estratégias para a redução da deriva de agrotóxicos em pulverizações hidráulicas. Planta Daninha, v.21, n.10, p.325-32, 2003.
Cunha, J. P. A. R.; Teixeira, M. M.; Fernandes, H. C. Avaliação do espectro de gotas de pontas de pulverização hidráulicas utilizando a técnica de difração do raio laser. Engenharia Agrícola, v.27, p.10-15, 2007.

Cunha, J. P. A. R.; Teixeira, M. M.; Vieira, R. F.; Fernandes, H. C. Deposição e deriva de calda fungicida aplicada em feijoeiro, em função de bico de pulverização e de volume de calda. Revista Brasileira de Engenharia Agrícola e Ambiental, v.9, n.1,p.133-138, 2005.

Gadanha Júnior, C. D. O desenvolvimento de produtos, equipamentos e componentes na aplicação de agrotóxicos, tendências e realidade: evolução dos equipamentos de aplicação. In: Simpósio Internacional de Tecnologia de Aplicação de Agrotóxicos: Eficiência Economia e Preservação da Saúde Humana e do Ambiente, 2., 2001, Jundiaí. Resumos... Jundiaí, I.A.C. 2001. CD Rom

Gandolfo, M. A; Sauer, A. V; Jesus, F. T. de; Afonso, M. Demanda de água atual e futura nas aplicações de agroquímicos. In: Simpósio de Recursos Hídricos do Norte e Centro-Oeste, 1, 2008, Cuiabá. Resumos... Cuiabá, 2008. p.85-98.

Grützmacher, D. D.; Grützmacher, A. D.; Agostinetto, D.; Loeck, A. E.; Roman, R.; Peixoto, S. C.; Renato Zanella, R. Monitoramento de agrotóxicos em dois mananciais hídricos no sul do Brasil. Revista Brasileira de Engenharia Agrícola e Ambiental, v.12, n.6, p.632-637, 2008.

Kuva, M. A.; Gravena, R.; Pitelli, R. A.; Christoffoleti, P. J.; Alves, P. L. C. A. Períodos de interferência das plantas daninhas na cultura da cana-de-açúcar. I - Tiririca (Cyperus rotundus). Planta Daninha, v.18, n.2, p.241-251, 2000.

Kuva, M. A.; Gravena, R.; Pitelli, R. A.; Christoffoleti, P. J.; Alves, P. L. C. A. Períodos de interferência das plantas daninhas na cultura da cana-de-açúcar. III - capim-braquiária (Brachiaria decumbens) e capim-colonião (Panicum maximum). Planta Daninha, v.21, n.1, p.37-44, 2003.

Pinho, A. P.; Matos, A. T.; Costa, L. M.; Morris, L. A.; Martinez, M. A. Modelagem de retenção de herbicidas em zonas riparias. Revista Brasileira de Engenharia Agrícola e Ambiental, v.10, n.4, p.896-902, 2006.

Roman, E. S.; Vargas, L.; Ribeiro, M. C. F.; LUIZ, A. R. M. Influencia do orvalho e volume de calda de aplicação na eficácia do glyphosate na dessecação de Brachiaria plantaginea. Planta Daninha, v.22, n.3, p.479-482, 2004.

Santos, S. R.; Maciel, A. J. S. Proposta metodológica utilizando ferramentas de qualidade na avaliação do processo de pulverização. Engenharia Agrícola, v.26, n.2, p.627-636, 2006.

SBCPD - Sociedade Brasileira da Ciência das Plantas Daninhas. Comitê Brasileiro de Resistência de Plantas aos Herbicidas. Identificação e manejo de plantas daninhas resistentes aos herbicidas. Londrina: 2000. 32p.

Schroder, E. P.; Loeck, A. E. Avaliação do sistema de pulverização eletrostática aérea na redução do volume de calda e dosagem do herbicida glifosate. Revista Brasileira de Agrociências, v.12, n.3, p.319-323, 2006.

Tomazela, M. S.; Martins, D.; Marchi, S. R.; Negrisoli, E. Avaliação da deposição da calda de pulverização em função da densidade populacional de Brachiaria plantaginea, do volume e do ângulo de aplicação. Planta Daninha, v.24, n.1, p.183-189, 2006. 